\title{
Selective and Efficient Removal of Volatile Organic Compounds by Channel-type Gamma-Cyclodextrin Assembly through Inclusion Complexation
}

\author{
Asli Celebioglu, ${ }^{\dagger}$ Semran ipek, ${ }^{\ddagger}$ Engin Durgun, ${ }^{\dagger}$ and Tamer Uyar*, ${ }^{\dagger}{ }^{\dagger}$ \\ ${ }^{\dagger}$ Institute of Materials Science \& Nanotechnology, UNAM-National Nanotechnology Research Center, Bilkent University, Ankara \\ 06800, Turkey \\ ${ }^{\ddagger}$ Department of Engineering Physics, Istanbul Medeniyet University, Istanbul 34700, Turkey
}

Supporting Information

\begin{abstract}
Cyclodextrins (CD), produced from enzymatic degradation of starch, are a form of biorenewable cyclic oligosaccharide which has an outstanding capability to form inclusion complexes with a variety of molecules including pollutants due to their toroid-shaped molecular structure. In this study, by a simple reprecipitation method, we obtained "channel-type" packing from $\gamma$-CD where $\mathrm{CD}$ molecules are stacked on top of each other to form long cylindrical channels. The $\gamma$-CD "channel-type" crystals have shown very effective removal of organic volatile compounds (VOCs; aniline and toluene) from the surroundings, whereas cage-type $\gamma$-CD could not entrap VOCs from the same environment. Encapsulation capability of channel-type $\gamma$-CD is at a $\sim 2: 1$ and $\sim 1: 1$ molar

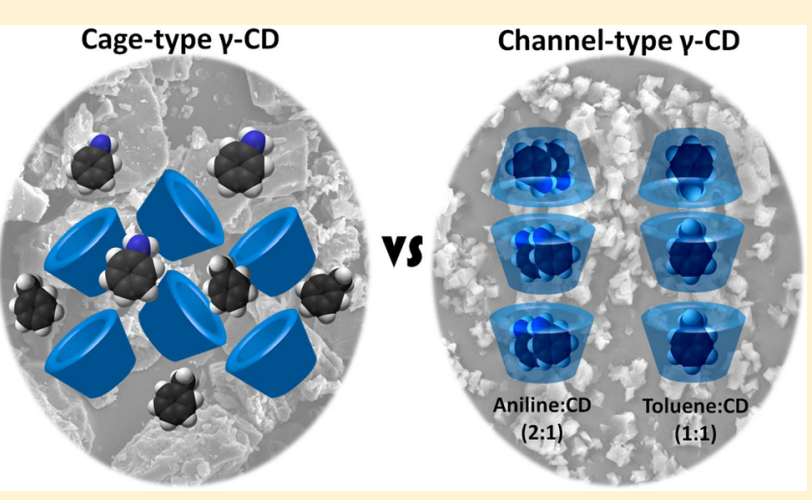
ratio for aniline/CD and toluene/CD, respectively. Thus, channel-type $\gamma$-CD crystals have shown higher removal efficiency for aniline compared to toluene. Channel-type $\gamma$-CD is also able to remove aniline selectively from surroundings. Additionally, computational modeling studies suggested that single $\gamma$-CD cavity can host two molecules of aniline or toluene for the complexation, yet, aniline is more insistent to make a complex with the $\gamma$-CD cavity when compared to toluene. We show that channel-type $\gamma$-CD can remove VOCs molecules (aniline and toluene) as efficiently as activated carbon. Hence, being a starchbased biorenewable cyclic oligosaccharide in the form of white powder, the use of "channel-type" $\gamma$-CD crystals could be a competitive alternative to activated carbon as an adsorbent for the VOC removal/filtering.
\end{abstract}

\section{INTRODUCTION}

Supramolecular structures offer new ways for environmental control thru noncovalent host-guest complexation with the pollutants. ${ }^{1-4}$ Among supramolecular structures, cyclodextrins (CDs) are one of the best-known examples since they are oligosaccharides obtained from enzymatic degradation of starch, and they have a relatively low cost. ${ }^{5-7} \mathrm{CDs}$ have a truncated cone-shape structure where they have a hydrophilic exterior, which makes CDs water-soluble, while the interior part has a lipophilic character, which provides an environment to host a variety of hydrophobic molecules to form inclusion complexation. $^{5-7}$ The most common cyclodextrins are named $\alpha$-CD, $\beta$-CD, and $\gamma$-CD having six, seven, or eight glucopyranose units in the cyclic structure, respectively. ${ }^{5}$ The depth of the cavities for these three native CDs is the same $(\sim 7.8 \AA)$, and as the number of glucopyranose units increases, so do the cavity diameters where the $\alpha$-CD, $\beta$-CD, and $\gamma$-CD have a cavity size of $\sim 6, \sim 8$, and $\sim 10 \AA$, respectively. ${ }^{5}$ The size/shape match between the host $C D$ cavity and guest molecules is the key factor for the formation of the cyclodextrin inclusion complex (CD-IC). In addition, binding forces (hydrophobic interactions, van der Waals attractions, hydrogen bonding, electrostatic interactions, etc.) determine the strength/stability of CD-IC. Hence, each CD type ( $\alpha$-CD, $\beta$ $\mathrm{CD}$, and $\gamma$-CD) shows specific capacity and stability to form CD-IC with the same host molecule. ${ }^{5}$ CDs can form inclusion complexes with hazardous chemicals and polluting substan$\mathrm{ces}^{2-4,8}$ therefore, they are used as an adsorbent material. ${ }^{2-4,9-11}$ In the case of wastewater treatment, since CDs are water-soluble, CDs are often cross-linked and used as a granular form. ${ }^{12}$ However, in the case of air filtration/purification, CDs can be employed as a powder form as-received. Native CDs $(\alpha-$ $\mathrm{CD}, \beta-\mathrm{CD}$, and $\gamma-\mathrm{CD})$ are crystalline materials having "cagetype" packing where each cavity is blocked by neighboring CD molecules, so the cavity is not available to form IC with the guest molecules. It has been shown that $\mathrm{CDs}$ can be transformed into "channel-type" packing where CD molecules

Received: March 15, 2017

Revised: June 6, 2017

Accepted: June 6, 2017

Published: June 6, 2017 
are stacked on top of each other to form long cylindrical channels by simple reprecipitation procedure where $\mathrm{CDs}$ are dissolved in water and precipitated into a nonsolvent. ${ }^{13}$ It has been also shown that these channel-type $C D$ powders are able to include both small molecules as well as long polymer chains when they are suspended in nonsolvent solution. ${ }^{13}$ Moreover, CD crystalline channel-type assembly can serve as an adsorbent to remove chlorinated aromatic compounds. ${ }^{14}$

In this study, we employed channel-type $\gamma$-CD powders to entrap volatile organic compounds (VOCs) for air filtration purposes. VOCs are one of the major sources of air pollution, and they are considered one of the most hazardous classes of pollutants due to their highly toxic and carcinogenic characteristics. ${ }^{15,16}$ Adsorption is considered as an efficient method for the removal and sometimes recovery of VOCs from the air. Although active carbon is a commonly used material to reduce the VOC degree in the surrounding area due to its high surface area and porous structure, ${ }^{17-20}$ adsorbents based on biorenewable resources is always on demand for filtration of such VOCs. Being derived from starch, $\mathrm{CD}$ is a promising candidate for the filtration of VOCs. ${ }^{10,21-24}$ In our recent studies, we have shown that $\mathrm{CD}$ functionalized electrospun polymeric nanofibers can remove VOCs. ${ }^{25-27}$ Moreover, we were able to obtain nanofibers of pure $\mathrm{CDs}$ such as $\gamma-\mathrm{CD}^{21}$ and chemically modified hydroxypropyl- $\beta$-cyclodextrin $(\mathrm{HP} \beta \mathrm{CD})$ and hydroxypropyl- $\gamma$-cyclodextrin $(\mathrm{HP} \gamma \mathrm{CD})$ for VOC removal. ${ }^{22}$ Yet, the removal efficiency of VOCs can be much higher by channeltype CD. In this study, we investigated the entrapment efficiency of channel-type $\gamma$-CD for two types of VOC molecules (i.e., aniline and toluene). Computational modeling studies were also performed to understand the inclusion complex formation between the $\gamma$-CD cavity and VOC molecules and the selectivity of the $\gamma$-CD cavity for VOC. Activated carbon was also tested for comparison, and it was found that the removal efficiency of channel-type $\gamma$-CD was comparable with the activated carbon.

\section{EXPERIMENTAL SECTION}

Materials. The gamma cyclodextrin $(\gamma-\mathrm{CD}, \mathrm{CAVAMAX}$ W8) was a gift from Wacker Chemie AG (Germany). Acetone (Sigma-Aldrich, 99.9\%), aniline (Sigma-Aldrich, 99\%), toluene (Sigma-Aldrich, $\geq 99.5 \%$ ), d6-DMSO (Merck), and activated charcoal (AC; Sigma-Aldrich, untreated, granular, 8-20 mesh) were purchased. Deionized water was used from a Millipore Milli-Q Ultrapure Water System. All the materials were used without any purification.

Formation of Channel-type $\boldsymbol{\gamma}$-CD. Here, homogeneous solutions of $\gamma$-CD $(5 \mathrm{~g})$ were prepared in water $(25 \mathrm{~mL})$ at 50 ${ }^{\circ} \mathrm{C}$. Thereafter, the clear and warm $\gamma$-CD solution was quickly poured into nonsolvent (acetone, $150 \mathrm{~mL}$ ) in which acetone was continuously stirred at $1000 \mathrm{rpm}$. A sudden precipitation of $\gamma$-CD in acetone was observed, and after 5 min of stirring, the suspension was filtered under a vacuum, then the white powder of channel-type $\gamma$-CD was obtained and dried in the hood overnight.

Characterizations and Measurements. The morphology of as-received cage-type $\gamma$-CD and channel-type $\gamma$-CD was analyzed by using scanning electron microscopy (SEM; Quanta $200 \mathrm{FEG}, \mathrm{FEI})$. The samples were coated with $5 \mathrm{~nm} \mathrm{Au} / \mathrm{Pd}$ before SEM imaging (PECS-682). A Brunauer-EmmettTeller (BET) surface area analyzer (Quantachrome, IQ-C model) was used to calculate the specific surface area of both cage-type and channel-type $\gamma$-CD crystalline aggregates.
Nitrogen adsorption isotherm data were collected at $77 \mathrm{~K}$ in the range of $0.00-1.00$ relative pressure. Prior to analysis, samples were located in a $9 \mathrm{~mm}$ cell and degassed for $12 \mathrm{~h}$ at $373 \mathrm{~K}$. The X-ray diffraction patterns of cage-type $\gamma$-CD and channel-type $\gamma$-CD were determined by X-ray diffractometer (XRD; X'Pert powder diffractometer, PANalytical) with $\mathrm{Cu} \mathrm{K} \alpha$ radiation in the $2 \theta=5-30^{\circ}$.

Entrapment of VOCs. The molecular filtration performance of cage-type and channel-type $\gamma$-CD was evaluated by entrapping VOC (aniline and toluene) vapors. For this experiment, $10 \mathrm{~mL}$ of aniline or toluene or aniline+toluene (1:1 volume ratio) was put into glass Petri dishes and then placed at the bottom of the desiccator $(30 \mathrm{~cm}$ (diameter) and $30 \mathrm{~cm}$ (height)). For time dependent tests, the desiccator was first saturated with VOCs for $12 \mathrm{~h}$ just before the experiments. Then, the channel-type and cage-type $\gamma$-CD samples were placed into the desiccator and sealed. Samples were exposed to a VOC atmosphere at room temperature $\left(23 \pm 1{ }^{\circ} \mathrm{C}\right)$; afterward, the $\gamma$-CD samples were taken out of the desiccators and kept in a suction hood for $1 \mathrm{~h}$ in order to remove the VOC molecules that were just adsorbed and could not form an inclusion complex (IC) with $\gamma$-CD molecules. In order to see the volume/dimension factor of the VOC test environment, we have performed a toluene (since it has much higher vapor pressure than aniline) entrapment test in a much smaller volume (in a $50 \mathrm{~mL}$-volume glass vial). As an experimental detail, $5 \mathrm{~mL}$ of toluene is placed in the $50 \mathrm{~mL}$ glass vial, and 0.1 $\mathrm{g}$ of each channel-type $\gamma$-CD and cage-type $\gamma$-CD powder was tested. The CD powder samples were placed in a $3 \mathrm{~mL}$ small glass vial (with an open lid to have full contact with toluene vapor, but the glass vial prevents direct contact of the $C D$ samples with the liquid toluene), and these $3 \mathrm{~mL}$ small glass vials containing $\mathrm{CD}$ samples were directly placed in the $50 \mathrm{~mL}$ glass vial having $5 \mathrm{~mL}$ of toluene in it and were sealed. The toluene entrapment experiment was performed for $24 \mathrm{~h}$ at RT $\left(23 \pm 1{ }^{\circ} \mathrm{C}\right)$ for both channel-type $\gamma$-CD and cage-type $\gamma$-CD.

Additional entrapment tests were also performed in the desiccator in which $\gamma$-CD samples were exposed to VOCs by different experimental pathways. Initially, time dependent removal of aniline and toluene by channel-type $\gamma$-CD was performed for a $24 \mathrm{~h}$ period, and for comparison, cage-type $\gamma$ $\mathrm{CD}$ was also exposed to aniline and toluene for $24 \mathrm{~h}$. A summary of the further entrapment tests is as follows: (i) Pristine channel-type $\gamma$-CD was exposed to aniline or toluene vapor. (ii) pristine channel-type $\gamma$-CD was exposed to aniline +toluene vapor, (iii) Aniline exposed channel-type $\gamma$-CD (aniline $/ \gamma$-CD) was exposed to toluene vapor. (iv) Toluene exposed channel-type $\gamma$-CD (toluene $/ \gamma$-CD) was exposed to aniline vapor. All the exposure tests were performed for $24 \mathrm{~h}$ at room temperature $\left(23 \pm 1{ }^{\circ} \mathrm{C}\right)$. Additionally, a well-known adsorbent, activated carbon (AC, BET $=600-800 \mathrm{~m}^{2} / \mathrm{g}, 8-20$ mesh, untreated) was used as another control sample during entrapment experiments, and it was exposed to aniline+toluene vapor for $24 \mathrm{~h}$. All the entrapment experiments were repeated three times.

The entrapped amount of VOC was analyzed by using a proton nuclear magnetic resonance $\left({ }^{1} \mathrm{H}\right.$ NMR; Bruker D PX$400)$ system. The $\gamma$-CD samples were dissolved in $d 6-\mathrm{DMSO}$ (20g/L concentration) after being exposed to VOC. The ${ }^{1} \mathrm{H}$ NMR spectra were recorded at $400 \mathrm{MHz}$ and at 16 total scans. The molar ratios between VOC/CD were determined by integrating the peak ratio of the characteristic chemical shifts $(\delta)$ corresponding to $\gamma$-CD, aniline, and toluene by using NMR 
(a)

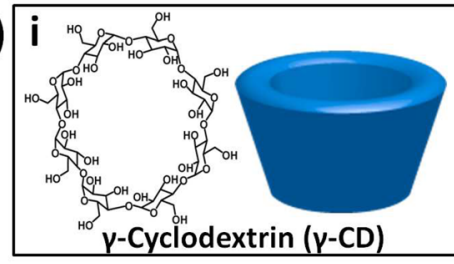

(b)

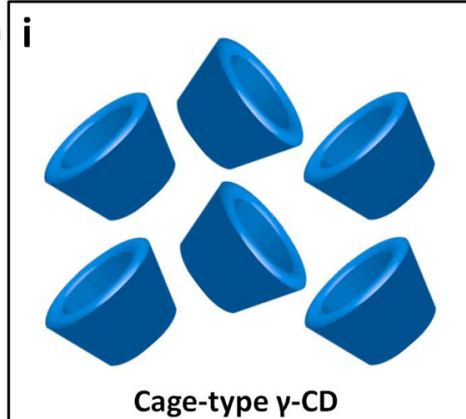

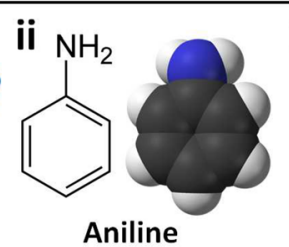

Aniline

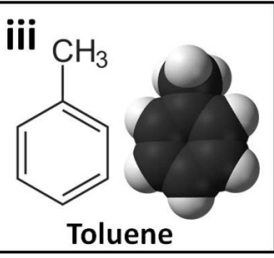

ii

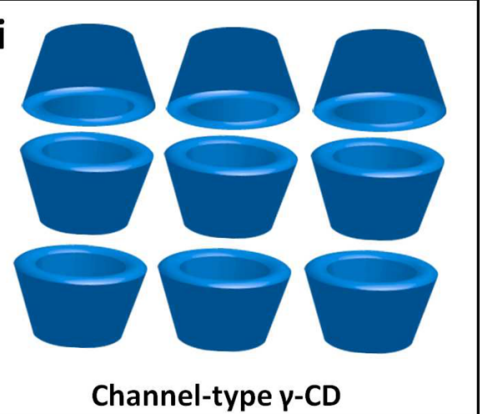

(c)

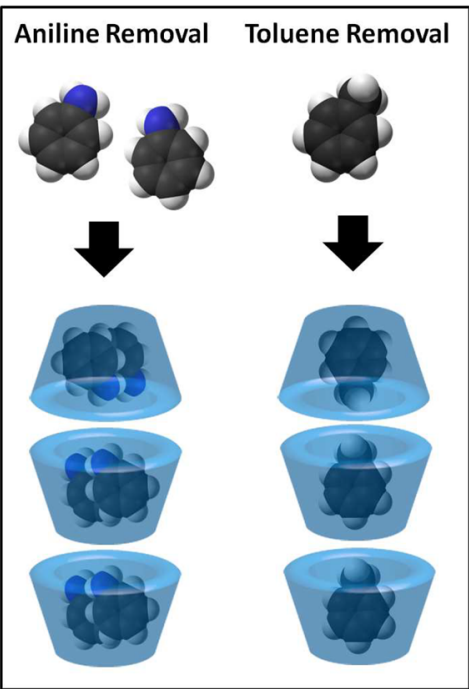

Figure 1. (a) Chemical structure and the schematic representation of (i) $\gamma$-CD molecule, (ii) aniline, and (iii) toluene. (b) Schematic representation of packing structures of (i) cage-type $\gamma$-CD and (ii) channel-type $\gamma$-CD. (c) Schematic representation of VOC entrapment by channel-type $\gamma$-CD.

software. The particular peaks belonging to aniline and toluene were observed in the aromatic region of the NMR spectrum (6.7 and 7.1 ppm for aniline, 7.1 and $7.2 \mathrm{ppm}$ for toluene). The molar ratios were calculated by taking into account the integration of aniline, toluene aromatic peaks, and the $\gamma$-CD's characteristic peak at about $4.8 \mathrm{ppm}$ for the d6-DMSO system. Three sets of samples were used for the NMR measurements to quantify the molar ratio of VOC/CD. A thermal Gravimetric Analyzer (TGA; Q500, TA Instruments) was performed to investigate temperature shifts for the evaporation of aniline and toluene for the VOC/CD samples which could reveal inclusion complexation between $\gamma$-CD and VOC molecules. In addition, TGA data were also used for the calculation of the entrapped amount of aniline and toluene by channel-type $\gamma$-CD. The TGA of the samples was carried out from 25 to $600{ }^{\circ} \mathrm{C}$ at a $20{ }^{\circ} \mathrm{C} /$ min heating rate, and $\mathrm{N}_{2}$ was used as a purge gas.

Computational Method. The calculations were performed by using density functional theory ${ }^{28,29}$ within the generalized gradient approximation ${ }^{30}$ including van der Waals correction, ${ }^{31}$ as implemented in the Vienna ab initio simulation package. ${ }^{32,33}$ The pseudopotentials of the elements were described by projector augmented-wave method (PAW) ${ }^{34}$ using a planewave basis set with a kinetic energy cutoff of $500 \mathrm{eV}$. The initial structure of $\gamma$-CD was obtained from the Cambridge Structural Database. $^{35}$ The guest molecules, pristine $\gamma$-CD, and their ICs were relaxed using the Kosugi algorithm without any constraints by setting convergence criteria on the total energy and force to $10^{-5} \mathrm{eV}$ and $10^{-2} \mathrm{eV} / \AA$, respectively.

\section{RESULTS AND DISCUSSION}

Structural Characterization. The as-received $\gamma-\mathrm{CD}$ is a white crystalline powder having a crystal structures called "cagetype" packing where each cavity is blocked by neighboring CD molecules (Figure 1). The diffraction pattern of as-received $\gamma$ $\mathrm{CD}$ has characteristic peaks at $2 \theta=12.0,14.4$, and $21.7^{\circ}$, and SEM imaging shows that the as-received $\gamma$-CD has crystals with irregular shapes and sizes (Figure 2a,b). On the other hand, using the simple reprecipitation method, ${ }^{13} \gamma$-CD can be transformed into "channel-type" packing where CD molecules are stacked on top of each other to form long cylindrical channels (Figure 1). Here, we successfully produced channel-
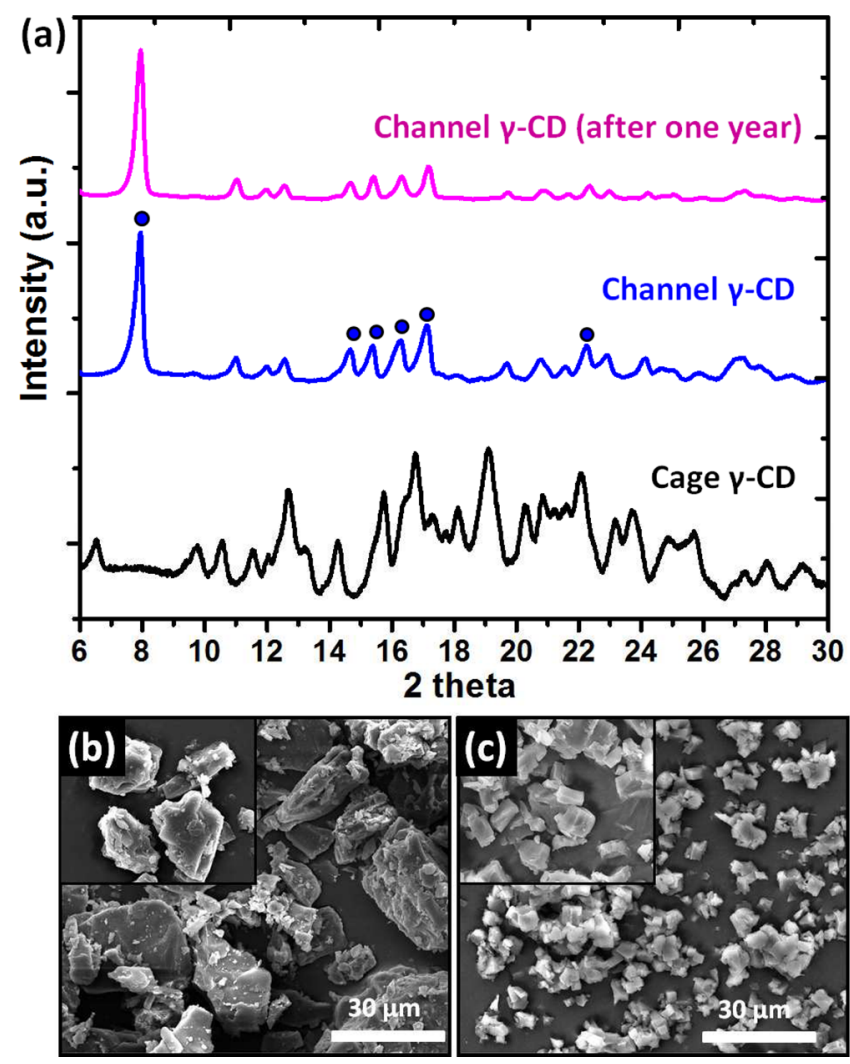

Figure 2. (a) XRD diffraction patterns of cage $\gamma$-CD, channel $\gamma$-CD, and channel $\gamma$-CD after one year of storage (in refrigerator at $+4{ }^{\circ} \mathrm{C}$ ). The representative SEM images of (b) as-received cage-type $\gamma$-CD and (c) channel-type $\gamma$-CD.

type $\gamma$-CD as proved by XRD in which the fingerprint diffraction pattern of the $\gamma$-CD channel-type is reported in the literature. $^{13}$ The characteristic peaks at $2 \theta=7.9,15.4,16.2$, 17.1, and $22.2^{\circ}$ was recorded by XRD (Figure 2a). Rusa et al. reported that the transition of cage-type $\gamma$-CD to channel-type $\gamma$-CD in a nonsolvent system (acetone), without using a guest molecule, originates from the water molecules' orientation inside and outside of the $\mathrm{CD}$ cavity, which form strong 

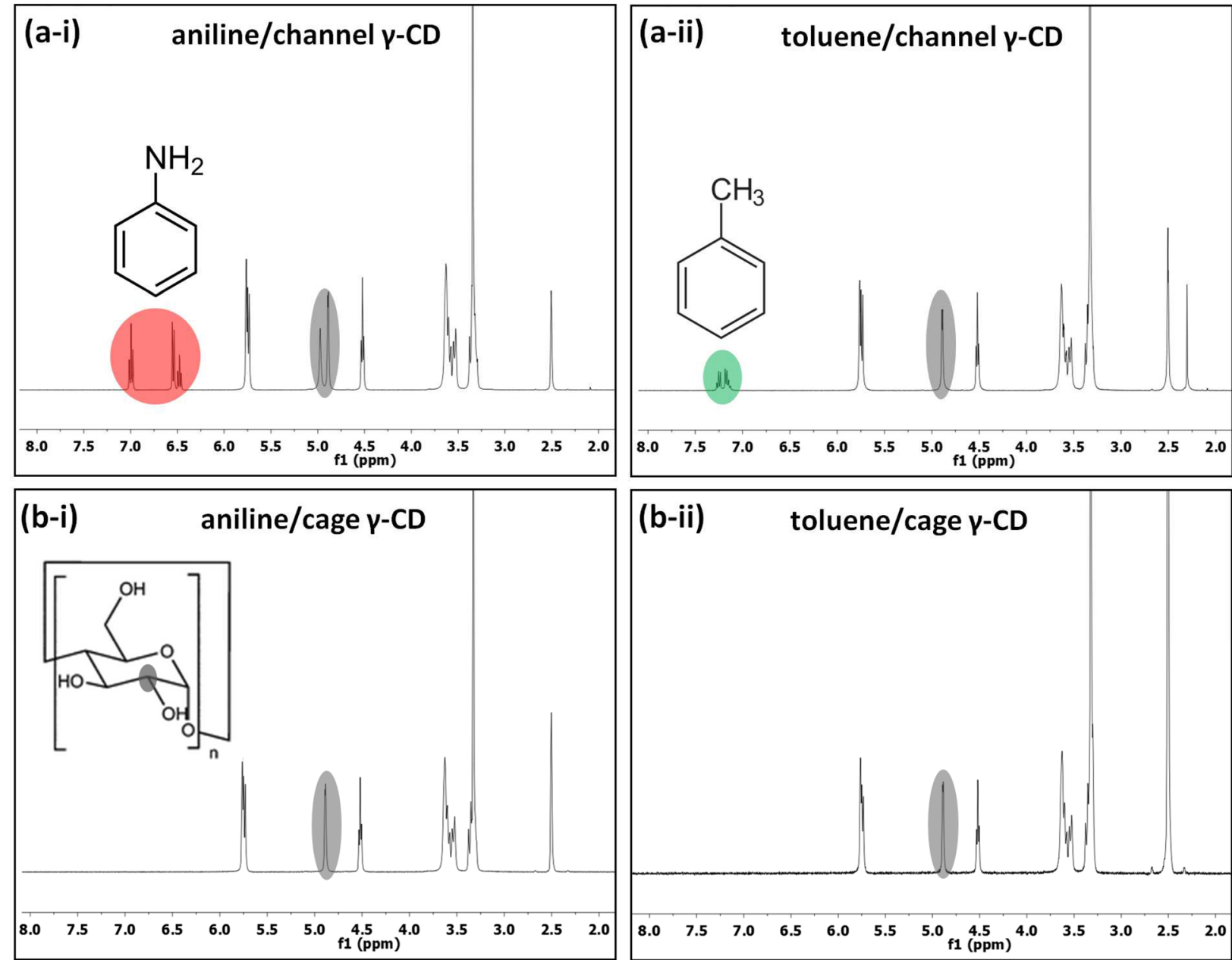

Figure 3. Representative ${ }^{1} \mathrm{H}$ NMR spectra of (a) channel $\gamma$-CD and (b) cage $\gamma$-CD exposed to (i) aniline and (ii) toluene vapor, which were dissolved in d6-DMSO.

hydrogen bonds so as to keep the crystalline structure in a columnar form. ${ }^{13}$ It is know that the channel-type $\gamma$-CD structure is not stable unless there is a guest molecule inside; however, the XRD result indicated that patterns did not change even after one year under the storage conditions (refrigerator at $+4{ }^{\circ} \mathrm{C}$ ), revealing the stability of the structure under these storage conditions (Figure 2a). In addition, SEM imaging shows that the crystal size for channel-type $\gamma$-CD is smaller and has a more regular shape (Figure 2c) when compared to that of as-received $\gamma$-CD crystals (Figure $2 \mathrm{~b}$ ). The BET measurements showed that the specific surface area of the as-received cagetype $\gamma$-CD $\left(1.46 \mathrm{~m}^{2} / \mathrm{g}\right)$ is slightly higher than the reprecipitated channel-type $\gamma$-CD $\left(1.14 \mathrm{~m}^{2} / \mathrm{g}\right)$.

Entrapment of VOCs. Cyclodextrins (CDs) can be used for filtration due to their molecular cavity by forming noncovalent host-guest inclusion complexes with a variety of organic molecules. ${ }^{1-4,9-12}$ In our recent studies, we have also shown that electrospun nanofibers made of pure $\mathrm{CDs}^{21,22}$ and polymeric nanofibers functionalized with $\mathrm{CDs}^{25-27}$ are quite effective to capture VOCs for air filtration purposes. Here, we have tested the molecular filtration capacity of the channel-type $\gamma$-CD by exposing them into vapor of aniline and toluene. It is anticipated that the entrapment of VOC by $\gamma$-CD would take place through inclusion complexation in which VOC molecules will be captured by the $\mathrm{CD}$ cavity. For a comparison study, the as-received $\gamma$-CD sample was also tested at the same time. We have placed both as-received $\gamma$-CD (cage-type) and reprecipitated CD (channel-type) in a desiccator saturated with aniline or toluene vapor for a certain time period $(24 \mathrm{~h})$. Additionally, we have performed time-dependent VOC entrapment tests for the channel-type $\gamma$-CD sample, but we only performed a $24 \mathrm{~h}$ VOC entrapment test for cage-type $\gamma$-CD for the comparison. In order to see the volume/dimension factor of the VOC test environment, we have also performed a toluene entrapment test by channel-type $\gamma$-CD and cage-type $\gamma$-CD in a much smaller entrapment environment (i.e., $50 \mathrm{~mL}$-volume glass vial).

${ }^{1} \mathrm{H}$ NMR results revealed that the channel-type $\gamma$-CD effectively entrapped aniline and toluene in the desiccator test environment due to the available long cylindrical channels for the entrapment (Figure 3a-i,ii). On the other hand, under the same conditions, cage-type $\gamma$-CD could not entrap the VOC molecules from the surrounding area possibly because each $\mathrm{CD}$ cavity is blocked by the neighboring $\mathrm{CD}$ molecule, and therefore the $\mathrm{CD}$ cavity could not be available for the entrapment of VOCs (Figure 3b-i,ii). Similar to the desiccator test environment, channel-type $\gamma$-CD could entrap toluene, whereas cage-type $\gamma$-CD could not entrap toluene when a much smaller entrapment environment (i.e., $50 \mathrm{~mL}$ volume) was used (Figure S1, see Supporting Information). This result clearly indicated that the entrapment of VOC is due to inclusion complexation between VOC molecules (aniline and toluene) 
and the CD cavity. Even the cage-type $\gamma$-CD $\left(1.46 \mathrm{~m}^{2} / \mathrm{g}\right)$ has a higher specific surface area than channel-type $\gamma$-CD $\left(1.14 \mathrm{~m}^{2} /\right.$ $\mathrm{g}$ ), and both $\gamma$-CD types are in powder form; cage-type $\gamma$-CD could not entrap the VOCs because of the unavailable cavity for the complexation. Figure 4a shows the entrapment test of VOC
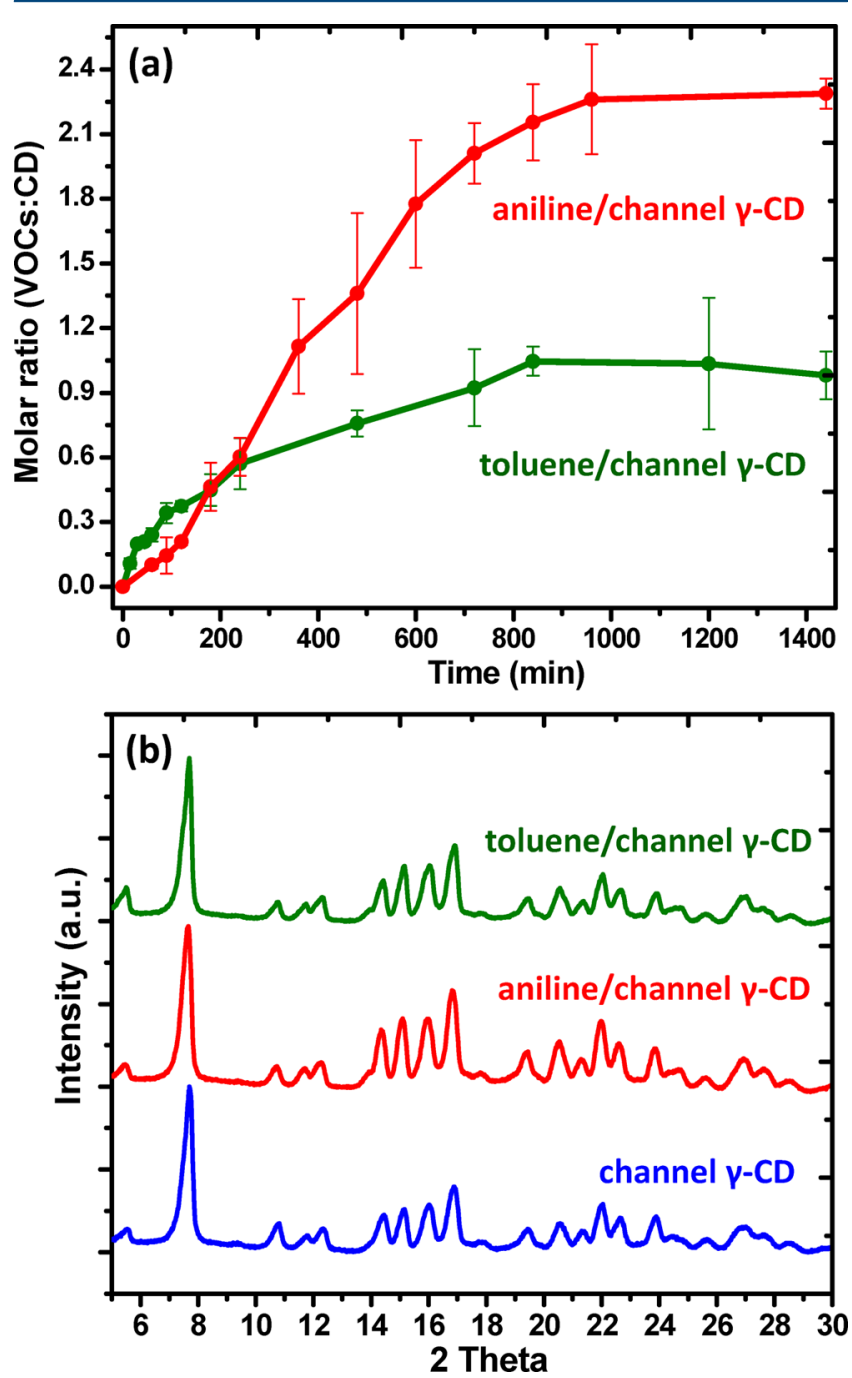

Figure 4. (a) Time dependent entrapment of aniline and toluene molecules by channel-type $\gamma$-CD. (b) XRD diffraction pattern of channel-type $\gamma$-CD samples before and after VOC entrapment tests.

by channel-type $\gamma$-CD with respect to exposure time. At the end of the entrapment test $(24 \mathrm{~h})$, the molar ratio of aniline $/ \gamma$-CD and toluene $/ \gamma$-CD was calculated as $(2.20 \pm 0.07): 1.00(\sim 2: 1)$ and $(0.98 \pm 0.11): 1.00(\sim 1: 1)$, respectively (Figure $4 \mathrm{a})$. This finding was similar to our previous report ${ }^{8}$ in which $\gamma$-CD formed $\sim 2: 1$ inclusion complexes (IC) with aniline, styrene, and phenol, whereas toluene, ethylbenzene, and $p$-xylene guests formed $\sim 1: 1$ inclusion complexes with $\gamma$-CD when the solution precipitation method was used for the CD-IC formation. The $\sim 1: 1$ ( $\gamma$-CD/toluene) inclusion complexation between channel-type $\gamma$-CD and toluene was also observed (Figure S1) in the case of using a smaller entrapment environment (i.e., $50 \mathrm{~mL}$ volume). This finding suggests that the toluene molecule prefers 1:1 inclusion complexation with channel-type $\gamma$-CD regardless of the volume/dimension of the entrapment environment.
On the other hand, in our very recent report ${ }^{21}$ in which a similar entrapment test was followed as in the present study, an electrospun $\gamma$-CD nanofibrous web could entrap aniline and toluene vapor, but the molar ratio of aniline $/ \gamma-\mathrm{CD}$ and toluene $/ \gamma$-CD was about $\sim 1: 1$ and $\sim 0.7: 1$, respectively. Although, the specific surface area of electrospun $\gamma$-CD nanofibers $\left(4.38 \mathrm{~m}^{2} / \mathrm{g}\right)^{21}$ was 4 times higher than that of channel-type $\gamma$-CD $\left(1.14 \mathrm{~m}^{2} / \mathrm{g}\right)$, the present study revealed that the complexation efficiency of channel-type $\gamma$-CD with VOCs (aniline and toluene) was higher here. It is worth it to mention that in the case of $\gamma$-CD nanofibers, ${ }^{21} \mathrm{CD}$ molecules were in an amorphous state without forming any particular crystalline packing structure. For the channel-type $\gamma$-CD sample, the CD cavities form a long cylinder which seems to be more accessible for the complexation. Therefore, this sample has shown more efficient removal of VOCs. So, the specific surface area is not the key player for the entrapment of VOCs. That is, even though cage-type $\gamma$-CD $\left(1.46 \mathrm{~m}^{2} / \mathrm{g}\right)$ has a slightly higher surface area than the channel-type $\gamma$-CD $\left(1.14 \mathrm{~m}^{2} / \mathrm{g}\right)$, it did not capture any VOCs at all. So, it is more about the packing structure of the CD molecules, which are accessible sites for the VOC entrapment. After the entrapment experiment, we analyzed channel-type $\gamma$-CD by XRD, and it was observed that $\gamma$-CDs still kept their initial channel-type packing structures (Figure 4b).

Figure $4 \mathrm{a}$ also indicates that the removal capacity of the channel-type $\gamma$-CD has increased with time and the VOC entrapment reached the steady-state after $15 \mathrm{~h}$. The entrapping efficiency of $\gamma$-CD for the aniline was 2 times higher than that of toluene. The $\sim 2: 1$ molar ratio of aniline $/ \gamma$-CD clearly indicates that the $\gamma$-CD cavity is capable of hosting two aniline molecules, similar to our earlier report. ${ }^{8}$ To evaluate the results more practically, we have also calculated molar ratio values in terms of milligrams per gram (VOCs/CD), and this provided better understanding for the VOC entrapment capacity of $1 \mathrm{~g}$ of $\gamma$-CD from the environment. The entrapment of aniline and toluene by channel-type $\gamma$-CD was calculated as $144 \mathrm{mg} / \mathrm{g}$ and $71 \mathrm{mg} / \mathrm{g}$, respectively.

Thermogravimetric analysis (TGA) is a useful technique to confirm the inclusion complexation between $\mathrm{CDs}$ and VOC molecules. In the case of inclusion complexation within the $\mathrm{CD}$ cavity, the evaporation of the VOC molecules shifts to much higher temperature owing to the interaction with $\mathrm{CD}$ cavity. ${ }^{8,36}$ As clear from the TGA thermograms (Figure 5a), pure aniline and toluene are quite volatile and readily evaporated at low temperatures. Toluene is more volatile than aniline since toluene has a lower boiling point $\left(111^{\circ} \mathrm{C}\right)$ and higher vapor pressure $\left(26 \mathrm{mmHg}\right.$ at $25{ }^{\circ} \mathrm{C}$ ) when compared to aniline, which has a higher boiling point $\left(\sim 184{ }^{\circ} \mathrm{C}\right)$ and much lower vapor pressure $\left(0.7 \mathrm{mmHg}\right.$ at $\left.25{ }^{\circ} \mathrm{C}\right)$. The pristine channeltype $\gamma$-CD sample has two weight losses: the one below $100{ }^{\circ} \mathrm{C}$ was evaporation of water, and the second, which starts at 300 ${ }^{\circ} \mathrm{C}$, corresponds to the main degradation of $\gamma$-CD. It may be expected that acetone may be left since the aqueous $\mathrm{CD}$ solution is reprecipitated into acetone to obtain channel-type $\gamma$ $\mathrm{CD}$. From the ${ }^{1} \mathrm{H}$ NMR data, the residue of acetone which is calculated as $0.28 \%(\mathrm{w} / \mathrm{w})$ is very minimal (Figure S2), so channel-type $\gamma$-CD contains about $10 \%(\mathrm{w} / \mathrm{w})$ water only according to TGA data. For the channel-type $\gamma$-CD exposed to aniline (aniline $/ \gamma$-CD), besides the water evaporation below $100{ }^{\circ} \mathrm{C}$ and main degradation of $\mathrm{CD}$ above $300^{\circ} \mathrm{C}$, there is an additional weight loss observed between 150 and $300{ }^{\circ} \mathrm{C}$ which corresponds to the evaporation of aniline (Figure 5 a-i and a-ii). 

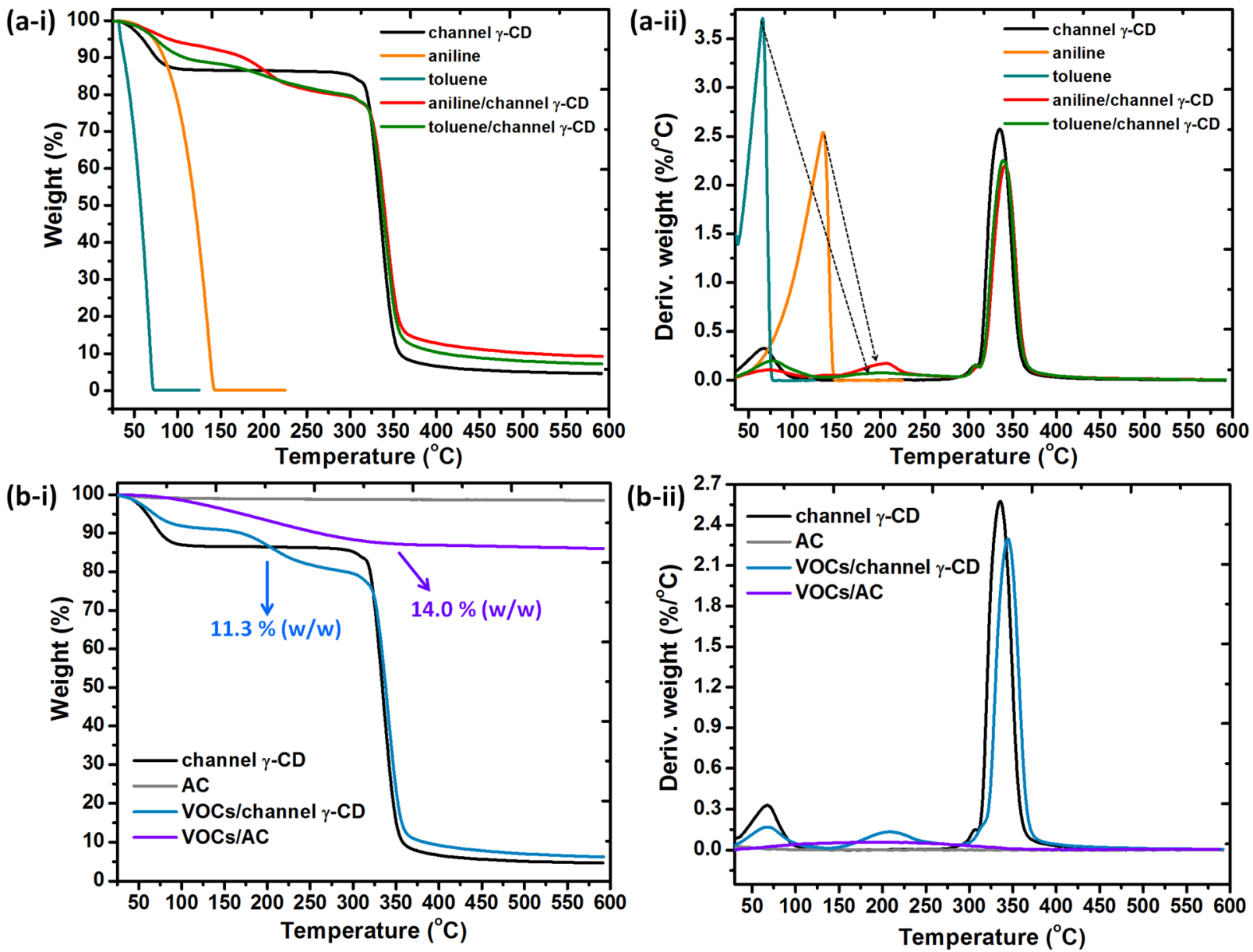

Figure 5. (i) TGA thermograms and (ii) their derivatives for (a) channel $\gamma$-CD, pure aniline, pure toluene, aniline/channel $\gamma$-CD (24 h aniline exposure), and toluene/channel $\gamma$-CD (24 h toluene exposure); (b) channel $\gamma$-CD, activated carbon (AC), VOCs/channel $\gamma$-CD and VOCs/AC.

The evaporation of aniline has shifted to very high temperature when compared to pure aniline because of the inclusion complexation with the $\mathrm{CD}$ cavity which the interaction prevents its evaporation. In the case of complexation, the thermal stability of the volatile guest molecule is expected to be increased due to guest-host interaction. ${ }^{8}$ So, TGA data have proved that the entrapment of aniline is through inclusion complexation with $\gamma$-CD. Because, in the case of a physical mixture where VOCs are only bounded outside of the cavity, the evaporation would take place at a much lower temperature. $^{36}$

Similar to the aniline $/ \gamma$-CD case, additional weight loss which corresponds to evaporation of toluene was observed at much higher temperatures $\left(150-300{ }^{\circ} \mathrm{C}\right)$ in the TGA thermogram of the channel-type $\gamma$-CD exposed to toluene (toluene $/ \gamma$-CD; Figure $5 \mathrm{a}-\mathrm{i}$ and a-ii). The presence of weight loss between 150 and $300{ }^{\circ} \mathrm{C}$ and higher thermal stability of toluene is further strong evidence for the complexation of toluene with $\gamma$-CD in this sample. A similar TGA thermogram was also obtained where toluene evaporation was recorded between 150 and $300{ }^{\circ} \mathrm{C}$ for the toluene/channel $\gamma$-CD sample in which the exposure of toluene vapor was performed in a 50 mL-volume glass vial (Figure S3).

In brief, TGA confirms that the entrapping of VOC (aniline and toluene) is through inclusion complexation. The TGA can also provide the weight of VOCs entrapped by the channel-type $\gamma$-CD. From TGA data, considering that the aniline or toluene only evaporated between 150 and $300{ }^{\circ} \mathrm{C}$, the amount of VOC present in the $\gamma$-CD was calculated as $\sim 13.5 \%(\mathrm{w} / \mathrm{w})$ and $8.5 \%$ (w/w) for aniline and toluene, respectively. The amount of toluene was calculated as $\sim 9.7 \%(\mathrm{w} / \mathrm{w})$ from the TGA data of the toluene/channel $\gamma$-CD sample in which the exposure of toluene vapor was performed in a $50 \mathrm{~mL}$-volume glass vial (Figure S3). Overall, this corresponds to a molar ratio of $\sim 2.1: 1$ for aniline $/ \gamma$-CD and $\sim 1.3: 1$ for toluene $/ \gamma$-CD. Although it is not exactly same, these findings are consistent with the NMR findings as discussed above, where a higher amount of aniline (144 mg/g) was entrapped when compared to toluene (71 mg/ g) by the channel-type $\gamma$-CD.

We have performed a series of comparative entrapment tests for channel-type $\gamma$-CD to see if there is any selectivity between aniline and toluene to be included inside the $\gamma$-CD cavity. Table 1 summarized the experimental pathways and the amount of VOCs in the samples in terms of molar ratio (VOC/CD). Here, three separate experimental environments were created in the desiccator with (i) aniline, (ii) toluene, and (iii) aniline +toluene vapor. Afterward, (i) pristine channel-type $\gamma$-CD and toluene exposed channel-type $\gamma$-CD (toluene $/ \gamma$-CD) were kept in an aniline environment. (ii) Pristine channel-type $\gamma$-CD and aniline exposed channel-type $\gamma$-CD (aniline $/ \gamma$-CD) were kept in toluene environment. (iii) Pristine channel-type $\gamma$-CDs were kept in an aniline+toluene environment for a $24 \mathrm{~h}$ time period. At the end of all these experiments, the amount of VOC in aniline $/ \gamma$-CD, toluene $/ \gamma$-CD, and pristine channel-type $\gamma$-CD 
Table 1. VOC Entrapment Tests for Pristine Channel-type $\gamma$ $\mathrm{CD}$ and VOC Exposed Channel-type $\gamma$-CD (Toluene/ $\gamma$-CD and Aniline $/ \gamma$-CD $)^{a}$

\begin{tabular}{|c|c|c|c|c|}
\hline $\begin{array}{c}\text { VOC } \\
\text { exposure }\end{array}$ & sample & $\begin{array}{l}\text { aniline } / \mathrm{CD}^{b} \\
\text { (molar ratio) }\end{array}$ & $\begin{array}{l}\text { toluene } / \mathrm{CD}^{b} \\
\text { (molar ratio) }\end{array}$ & $\begin{array}{l}\text { total } \mathrm{VOC} / \mathrm{CD}^{b} \\
\text { (molar ratio) }\end{array}$ \\
\hline \multirow[t]{2}{*}{ aniline } & $\begin{array}{l}\text { channel- } \\
\text { type } \gamma- \\
\text { CD }\end{array}$ & $2.01 \pm 0.14$ & & $2.01 \pm 0.14$ \\
\hline & $\begin{array}{l}\text { toluene } / \gamma \text { - } \\
\qquad \mathrm{CD}^{c}\end{array}$ & $1.86 \pm 0.11$ & $0.21 \pm 0.01$ & $2.08 \pm 0.11$ \\
\hline \multirow[t]{2}{*}{ toluene } & $\begin{array}{l}\text { channel- } \\
\text { type } \gamma- \\
\text { CD }\end{array}$ & $0.17 \pm 0.02$ & $0.82 \pm 0.12$ & $0.98 \pm 0.11$ \\
\hline & $\underset{\mathrm{CD}^{d}}{\operatorname{aniline} / \gamma-}$ & $0.20 \pm 0.02$ & $0.92 \pm 0.05$ & $1.12 \pm 0.06$ \\
\hline $\begin{array}{l}\text { aniline } \\
\text { +toluene }\end{array}$ & $\begin{array}{l}\text { channel } \gamma- \\
\text { CD }\end{array}$ & $1.58 \pm 0.06$ & $0.25 \pm 0.01$ & $1.82 \pm 0.07$ \\
\hline
\end{tabular}

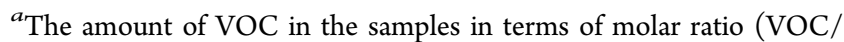
$\mathrm{CD}$ ) after $24 \mathrm{~h}$ of exposure to aniline or toluene or aniline+toluene $(1: 1, \mathrm{v} / \mathrm{v})$ vapor. The molar ratio of VOC/CD was calculated from ${ }^{1} \mathrm{H}$ NMR. All entrapment experiments were repeated three times $(n=3)$.

${ }^{b}$ The molar ratio of $\mathrm{CD}$ is 1:00. ${ }^{c}$ The $24 \mathrm{~h}$ toluene exposed channeltype $\gamma$-CD (toluene $/ \gamma$-CD); the initial molar ratio of toluene is $0.98 \pm$ 0.11 before the entrapment test. ${ }^{d}$ The $24 \mathrm{~h}$ aniline exposed channeltype $\gamma$-CD (aniline $/ \gamma$-CD); the initial molar ratio of aniline is $2.20 \pm$ 0.07 before the entrapment test.

was calculated by ${ }^{1} \mathrm{H}$ NMR studies. We found out that, in the case of the aniline environment, the entrapment molar ratio of aniline $/ \gamma$-CD is $(2.01 \pm 0.14): 1.00$ and $(1.86 \pm 0.11): 1.00$ for pristine channel-type $\gamma$-CD and toluene $/ \gamma$-CD, respectively, and toluene $/ \gamma-\mathrm{CD}$ ratio is only $(0.21 \pm 0.01): 1.00$ for the toluene $/ \gamma$-CD sample. This indicates that only $20 \%$ of toluene molecules remained in the $\gamma$-CD cavity, and the rest of the $\gamma$ $\mathrm{CD}$ cavity was occupied by aniline molecules with a much higher molar ratio $([1.86 \pm 0.11]: 1.00)$ when the sample was exposed to aniline vapor. For the exact opposite situation, in a toluene environment, the entrapment molar ratio of toluene $/ \gamma$ $\mathrm{CD}$ is $(0.82 \pm 0.12): 1.00$ and $(0.92 \pm 0.05): 1.00$ for pristine channel-type $\gamma$-CD and aniline $/ \gamma$-CD, respectively. Moreover, the aniline $/ \gamma-\mathrm{CD}$ ratio is $(0.17 \pm 0.02): 1.00$ and $(0.20 \pm$ 0.02):1.00 for pristine channel-type $\gamma-\mathrm{CD}$ and aniline $/ \gamma-\mathrm{CD}$, respectively. This indicates that only $10 \%$ of aniline molecules remained in the $\gamma$-CD cavity, and the rest of the $\gamma$-CD cavity was occupied by toluene molecules with a $(0.92 \pm 0.05): 1.00$ molar ratio of toluene/CD in the toluene vapor exposure test. In spite of the toluene vapor environment, it was interestingly observed that the pristine channel-type $\gamma$-CD also captured an aniline molecule which was released from the aniline $/ \gamma$-CD sample. The time dependent tests we initially performed also indicated that $\gamma$-CD tends to form inclusion complexes with aniline and toluene at $\sim 2: 1$ and $\sim 1: 1$ molar ratios (VOC/CD), respectively. In brief, the comparative test results supported this finding by demonstrating similar trends for the aniline and toluene vapor environment. Additionally, the pristine channeltype $\gamma$-CD was exposed to aniline+toluene vapor, and the VOC/CD molar ratio was calculated as $(1.58 \pm 0.06): 1.00$ and $(0.25 \pm 0.01): 1.00$ for aniline and toluene, respectively. As clearly seen, even in the mixed vapor, a higher amount of aniline was entrapped from the desiccator compared to toluene; even more toluene was expected in the environment since it has a more volatile nature (higher vapor pressure) than aniline. In brief, these results suggested the more favorable inclusion complex formation between aniline and $\gamma$-CD along with higher entrapment efficiency when compared to toluene. We can also conclude that the channel-type $\gamma$-CD enables the selective entrapment of aniline over toluene vapor from the surrounding area. As discussed in the following section below, we also performed computational modeling studies in order to understand the different complexation affinity for aniline and toluene by $\gamma$-CD cavity.

As is known, activated carbon (AC) is one of the most commonly used adsorbent materials for the removal of VOCs from the environment. ${ }^{37}$ On the other hand, the handling of AC material is a challenge. The AC materials are generally integrated into solid support, and they need an energy intensive regeneration process after their usage. All these drawbacks create problems during the practical applications of $\mathrm{AC}$ materials; therefore, easy-to-use, cost-effective, and biobased CD-based adsorbent materials could be an alternative to AC. ${ }^{38}$ Hence, we have also performed a comparative study by using AC. Here, we have exposed AC to the aniline+toluene mixture environment, and then we evaluated the results by using TGA. TGA measurements suggested that the channel-type $\gamma$-CD and AC entrapped $11.3 \%$ and $14.0 \%(\mathrm{w} / \mathrm{w})$ of VOC molecules from the environment with respect to total sample amount (Figure $5 \mathrm{~b}$ ). This result revealed that, although $\mathrm{AC}$ is one of the most commonly used adsorbents for VOC removal, channeltype $\gamma$-CD could also entrap VOC molecules as efficiently as $\mathrm{AC}$, in spite of the extremely high specific surface area of $\mathrm{AC}$ $\left(600-800 \mathrm{~m}^{2} / \mathrm{g}\right)$ when compared to channel-type $\gamma$-CD $(1.14$ $\left.\mathrm{m}^{2} / \mathrm{g}\right)$. Eventually, our results suggest that channel-type $\gamma$-CD might be a better alternative to AC as an adsorbent for VOC removal due to its biobased sustainability, being a white-colored powder, and nontoxic nature without a burden to the environment.

Computational Modeling of CD Complexation with VOCs. In order to elucidate the inclusion process of guest molecules (aniline and toluene) within the $\gamma$-CD cavity, we consider the structure and energetics of the inclusion complexes. First, the initial structures of $\gamma-\mathrm{CD},{ }^{35}$ aniline, and toluene are fully optimized in vacuum. The lowest energy conformations of guest molecule dimers are also found. The obtained results are consistent with recent spectroscopic studies in terms of binding energy and geometrical conformation of the dimer. $^{39,40}$ Since the $2: 1$ molar ratio is observed for aniline in the experimental part of the study, the dimer of two guest molecules is introduced into the cavity of $\gamma$-CD for a more proper comparison (Figure 6). The various locations and the complexation energy $\left(E_{\text {comp }}\right)$ for the lowest energy orientations are calculated as

$$
E_{\text {comp }}=E_{\mathrm{CD}}+E_{\text {dimer-guest }}-E_{\mathrm{IC}}
$$

where $E_{\mathrm{CD}}, E_{\text {dimer-guest }}$ and $E_{\mathrm{IC}}$ are the total energies of $\gamma-\mathrm{CD}$, the guest dimer (aniline or toluene), and their inclusion complex, respectively. The results are summarized in Table 2. According to the obtained results, all energies are comparable and do not indicate any significant difference.

Thus, to understand the inclusion propensity of $\gamma$-CD toward aniline and toluene, an additional guest molecule is initially placed $6 \AA$ away from the center of the $\gamma$-CD cavity and then moved toward $\gamma$-CD IC in $0.5 \AA$ steps as shown in Figure 6. At each moving step, all of the system is optimized except the coordinates of the incoming guest molecule in the moving direction, allowing any possible conformational changes. Remarkably, the incoming guest molecule triggers different conformational responses depending on the type of existing dimer in $\gamma$-CD. When an additional aniline molecule 


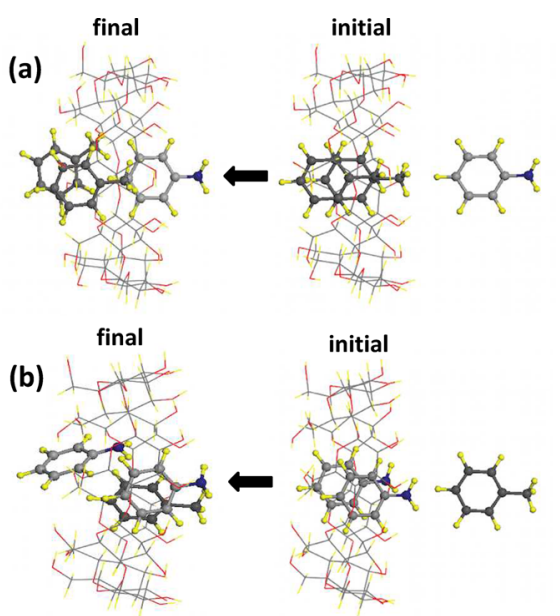

Figure 6. Side view of optimized structures of the guest (aniline and toluene) dimer and $\gamma$-CD inclusion complexes (IC) with incoming extra guest molecules toward it. Initial and final configurations when (a) an additional aniline molecule approaches toluene-toluene $/ \gamma$-CD IC and (b) when an additional toluene molecule approaches anilineaniline $/ \gamma$-CD IC. Gray, red, and yellow represent carbon, oxygen, and hydrogen atoms, respectively. For a better illustration, dark and light gray spheres represent carbon atoms of toluene and aniline molecules, respectively.

Table 2. Binding Energies of Pristine Guest Dimers and Complexation Energies of Guest Dimers within $\gamma$-CD Cavity $^{a}$

$\begin{array}{lccc} & \begin{array}{c}\text { aniline- } \\ \text { aniline }\end{array} & \begin{array}{c}\text { toluene- } \\ \text { toluene }\end{array} & \begin{array}{c}\text { aniline- } \\ \text { toluene }\end{array} \\ E_{\text {comp }}(\mathrm{kcal} / \mathrm{mol})(2: 1) & 22.37 & 25.62 & 25.30 \\ E_{\text {dimer }}(\mathrm{kcal} / \mathrm{mol}) & 1.61 & 3.0 & 2.07\end{array}$

$a(2: 1)$ denotes the molar ratio of guest molecule $/ \gamma$-CD.

approaches the (toluene dimer)- $\gamma$-CD-IC, the toluene dimer tends to leave out $\gamma$-CD together, as shown in Figure 6a. This result suggests that toluene molecules in $\gamma$-CD can be replaced by aniline when additional aniline molecules are present. However, when we repeat the same procedure for an additional toluene molecule approaching the (aniline dimer)- $\gamma$-CD-IC, the aniline dimer moves apart at the first place, trying to allow space for toluene in the cavity. This action also slightly deforms $\gamma$-CD. If toluene is further pushed inside, one of the aniline molecules tends to move out of the $\gamma$-CD leaving its pair aniline with toluene in $\gamma$-CD as illustrated in Figure $6 \mathrm{~b}$. Thus, it makes it harder to replace aniline molecules with toluene when compared to the previous case but can occur to some extent. Accordingly, although binding of the guest dimer to $\gamma$-CD is mainly governed by van der Waals interactions, the superiority of the $\pi-\pi$ interaction between aromatic guest dimers plays a key role for substitution. For instance, the toluene dimer energy is $3 \mathrm{kcal} / \mathrm{mol}$, which is almost double that of the aniline dimer energy (Table 2) suggesting a higher $\pi-\pi$ interaction for the toluene dimer. Briefly, our computational modeling studies show that both aniline and toluene can form 2:1 CD-IC with a very similar complexation energy; however, as it is also observed from the results, aniline is more insistent to be located in the CD cavity compared to toluene. In addition, the aniline dimer is not in demand to be replaced by toluene molecules, while toluene dimers tend to be replaced by an aniline molecule. Actually, this situation also clarifies the aniline selectivity by the $\gamma$-CD cavity during the entrapment studies. When we consider the molecular properties of aniline and toluene, we observe that toluene molecules ( $\log$ P: 2.39) are more hydrophobic compared to aniline $(\log$ P: 1.01$){ }^{41}$ Therefore, we may expect a more desirable interaction between the $\mathrm{CD}$ cavity and toluene molecules compared to between the aniline and $\mathrm{CD}$ cavity, because of more likely hydrophobic interactions between the aromatic ring and $\mathrm{CD}$ cavity. On the other hand, inclusion complexation with $\mathrm{CD}$ molecules is also governed by van der Waals interactions, hydrogen bonding, release of the high energy water, and a decrease in the strain energy in the CD cavity. ${ }^{42}$ The presence of a hydrogen bonding substituent on the guest aromatic rings leads to possible hydrogen bonds between $\mathrm{CD}$ and the guest molecule. ${ }^{43}$ When we checked the PSA (polar surface area) values of the concerned VOCs, we clearly observed that aniline molecules (PSA: $26.32 \AA^{2}$ ) contain polar sides as distinct from toluene (PSA: $0 \AA^{2}$ ), which may enable aniline to form hydrogen bonds with $\mathrm{CD}$ molecules in addition to other interactions. ${ }^{42,43}$ So, the $2: 1$ stoichiometric tendency of aniline $/ \gamma$-CD might also be explained by this favorable molecular structure of aniline which may facilitate an easier localization for aniline into the $C D$ cavity compared to toluene. Since there is not so much of a difference between the aniline $\left(95.3 \AA^{3}\right)$ and toluene $\left(100 \AA^{3}\right)$ molecular volumes, size match variations cannot be created during inclusion complexation. ${ }^{41}$

\section{CONCLUSION}

In this study, a channel-type $\gamma$-CD crystal was successfully obtained by a simple reprecipitation method as a white-colored and fine-powder form. The molecular entrapment performance of channel-type $\gamma$-CD was investigated by exposing them to VOCs: aniline and toluene vapor. We have observed that, while channel-type $\gamma$-CDs are able to entrap VOCs from the surroundings, as-received cage-type $\gamma$-CD could not remove VOCs from the same environment. ${ }^{1} \mathrm{H}$ NMR and TGA results revealed that the aniline encapsulation capability ( $\sim 2: 1$ aniline/ $\mathrm{CD}$ molar ratio) of channel-type $\gamma$-CD was significantly higher compared to that of toluene encapsulation $(\sim 1: 1$ toluene/CD molar ratio). Even channel-type $\gamma$-CD demonstrates selective entrapment for aniline molecules in the VOCs' mixture environment. The computational modeling studies also support our experimental data by indicating the more dominant tendency of $\mathrm{CD}$ cavities for maintaining the interaction with aniline compared to toluene molecules. TGA measurements prove the inclusion complex formation between CD and VOCs where a much higher evaporation temperature range (150-300 ${ }^{\circ} \mathrm{C}$ ) for VOCs was recorded in the case of VOC/channel $\gamma$-CD samples. Although channel-type $\gamma$-CD prominently have a lower surface area $\left(1.14 \mathrm{~m}^{2} / \mathrm{g}\right)$ compared to activated carbon (AC) $\left(600-800 \mathrm{~m}^{2} / \mathrm{g}\right)$, channel-type $\gamma$-CD $(11.3 \%(\mathrm{w} / \mathrm{w})$ with respect to sample) removed VOC molecules (aniline+toluene) as efficiently as $\mathrm{AC}(14 \%(\mathrm{w} / \mathrm{w})$ with respect to the sample). In short, our findings suggest that "channel-type" $\gamma$-CD crystals offer effective and selective filtering possibilities for the removal of VOCs for air filtration. Being a starch-based biorenewable cyclic oligosaccharide in the form of a white powder, the use of "channel-type" $\gamma$-CD crystals can contribute to development of new sustainable filtering materials for VOC removal/treatment as an alternative to carbon-based materials or any other synthetic filtering materials. 


\section{ASSOCIATED CONTENT}

\section{S Supporting Information}

The Supporting Information is available free of charge on the ACS Publications website at DOI: 10.1021/acs.iecr.7b01084.

${ }^{1} \mathrm{H}$ NMR spectra of channel-type $\gamma$-CD and cage-type $\gamma$ $\mathrm{CD}$ exposed to toluene vapor (in a $50 \mathrm{~mL}$-volume glass vial), ${ }^{1} \mathrm{NMR}$ of channel-type $\gamma$-CD, and TGA thermogram of toluene/channel $\gamma$-CD (exposed to toluene vapor in $50 \mathrm{~mL}$-volume glass vial) (PDF)

\section{AUTHOR INFORMATION}

\section{Corresponding Author}

*Tel.: +90-3122908987. E-mail: tamer@unam.bilkent.edu.tr.

\section{ORCID $\odot$}

Engin Durgun: 0000-0002-0639-5862

Tamer Uyar: 0000-0002-3989-4481

\section{Notes}

The authors declare no competing financial interest.

\section{ACKNOWLEDGMENTS}

T.U. thanks the Turkish Academy of Sciences-Outstanding Young Scientists Award Program (TUBA-GEBIP) for partial funding. A.C. thanks TUBITAK (project \#113Y348) for a postdoctoral fellowship.

\section{REFERENCES}

(1) Albelda, M. T.; Frías, J. C.; García-España, E.; Schneider, H.-J. Supramolecular complexation for environmental control. Chem. Soc. Rev. 2012, 41, 3859-3877.

(2) Fourmentin, S.; Ciobanu, A.; Landy, D.; Wenz, G. Space filling of $\beta$-cyclodextrin and $\beta$-cyclodextrin derivatives by volatile hydrophobic guests. Beilstein J. Org. Chem. 2013, 9, 1185-1191.

(3) Massaro, M.; Colletti, C. G.; Lazzara, G.; Guernelli, S.; Noto, R.; Riela, S. Synthesis and Characterization of Halloysite-Cyclodextrin Nanosponges for Enhanced Dyes Adsorption. ACS Sustainable Chem. Eng. 2017, 5, 3346.

(4) Shao, D.; Sheng, G.; Chen, C.; Wang, X.; Nagatsu, M. Removal of polychlorinated biphenyls from aqueous solutions using $\beta$-cyclodextrin grafted multiwalled carbon nanotubes. Chemosphere 2010, 79, 679685.

(5) Szejtli, J. Introduction and general overview of cyclodextrin chemistry. Chem. Rev. 1998, 98, 1743-1754.

(6) Hedges, A. R. Industrial applications of cyclodextrins. Chem. Rev. 1998, 98, 2035-2044.

(7) Del Valle, E. M. Cyclodextrins and their uses: a review. Process Biochem. 2004, 39, 1033-1046.

(8) Uyar, T.; Hunt, M. A.; Gracz, H. S.; Tonelli, A. E. Crystalline cyclodextrin inclusion compounds formed with aromatic guests: Guest-dependent stoichiometries and hydration-sensitive crystal structures. Cryst. Growth Des. 2006, 6, 1113-1119.

(9) Landy, D.; Mallard, I.; Ponchel, A.; Monflier, E.; Fourmentin, S. Remediation technologies using cyclodextrins: an overview. Environ. Chem. Lett. 2012, 10, 225-237.

(10) Mallard Favier, I.; Baudelet, D.; Fourmentin, S. VOC trapping by new crosslinked cyclodextrin polymers. J. Inclusion Phenom. Mol. Recognit. Chem. 2011, 69, 433-437.

(11) Schofield, W.; Bain, C.; Badyal, J. Cyclodextrin-functionalized hierarchical porous architectures for high-throughput capture and release of organic pollutants from wastewater. Chem. Mater. 2012, 24, $1645-1653$.

(12) Morin-Crini, N.; Crini, G. Environmental applications of waterinsoluble $\beta$-cyclodextrin-epichlorohydrin polymers. Prog. Polym. Sci. 2013, 38, 344-368.
(13) Rusa, C. C.; Bullions, T. A.; Fox, J.; Porbeni, F. E.; Wang, X.; Tonelli, A. E. Inclusion compound formation with a new columnar cyclodextrin host. Langmuir 2002, 18, 10016-10023.

(14) Kida, T.; Nakano, T.; Fujino, Y.; Matsumura, C.; Miyawaki, K.; Kato, E.; Akashi, M. Complete removal of chlorinated aromatic compounds from oils by channel-type $\gamma$-cyclodextrin assembly. Anal. Chem. 2008, 80, 317-320.

(15) De Crom, J.; Claeys, S.; Godayol, A.; Alonso, M.; Anticó, E.; Sanchez, J. M. Sorbent-packed needle microextraction trap for benzene, toluene, ethylbenzene, and xylenes determination in aqueous samples. J. Separ. Scien. 2010, 33, 2833-2840.

(16) Irusta, S.; Pina, M.; Menendez, M.; Santamaria, J. Development and application of perovskite-based catalytic membrane reactors. Catal. Lett. 1998, 54, 69-78.

(17) Bradley, R.; Rand, B. On the physical adsorption of vapors by microporous carbons. J. Colloid Interface Sci. 1995, 169, 168-176.

(18) Majumdar, S.; Bhaumik, D.; Sirkar, K.; Simes, G. A pilot-scale demonstration of a membrane-based absorption-stripping process for removal and recovery of volatile organic compounds. Environ. Prog. 2001, 20, 27-35.

(19) Vermisoglou, E.; Georgakilas, V.; Kouvelos, E.; Pilatos, G.; Viras, K.; Romanos, G.; Kanellopoulos, N. Sorption properties of modified single-walled carbon nanotubes. Microporous Mesoporous Mater. 2007, 99, 98-105.

(20) Bradley, R. H.; Smith, M. W.; Andreu, A.; Falco, M. Surface studies of novel hydrophobic active carbons. Appl. Surf. Sci. 2011, 257, 2912-2919.

(21) Celebioglu, A.; Uyar, T. Electrospun gamma-cyclodextrin $(\gamma$ CD) nanofibers for the entrapment of volatile organic compounds. RSC Adv. 2013, 3, 22891-22895.

(22) Celebioglu, A.; Sen, H. S.; Durgun, E.; Uyar, T. Molecular entrapment of volatile organic compounds (VOCs) by electrospun cyclodextrin nanofibers. Chemosphere 2016, 144, 736-744.

(23) Mauri-Aucejo, A. R.; Llobat-Estellés, M.; Egea, M. G.; Guillem, C.; Amorós, P. Samplers for VOCs in air based on cyclodextrin-silica hybrid microporous solid phases. Analyst 2012, 137, 1275-1283.

(24) Lumholdt, L.; Fourmentin, S.; Nielsen, T. T.; Larsen, K. L. Removal of volatile organic compounds using amphiphilic cyclodextrin-coated polypropylene. Beilstein J. Org. Chem. 2014, 10, 27432750.

(25) Uyar, T.; Havelund, R.; Nur, Y.; Balan, A.; Hacaloglu, J.; Toppare, L.; Besenbacher, F.; Kingshott, P. Cyclodextrin functionalized poly (methyl methacrylate) (PMMA) electrospun nanofibers for organic vapors waste treatment. J. Membr. Sci. 2010, 365, 409-417.

(26) Kayaci, F.; Sen, H. S.; Durgun, E.; Uyar, T., Electrospun nylon 6, 6 nanofibers functionalized with cyclodextrins for removal of toluene vapor. J. Appl. Polym. Sci. 2015, 132.4194110.1002/app.41941

(27) Kayaci, F.; Uyar, T. Electrospun polyester/cyclodextrin nanofibers for entrapment of volatile organic compounds. Polym. Eng. Sci. 2014, 54, 2970-2978.

(28) Kohn, W.; Sham, L. J. Self-consistent equations including exchange and correlation effects. Phys. Rev. 1965, 140, A1133.

(29) Hohenberg, P.; Kohn, W. Inhomogeneous electron gas. Phys. Rev. 1964, 136, B864.

(30) Perdew, J. P.; Chevary, J. A.; Vosko, S. H.; Jackson, K. A.; Pederson, M. R.; Singh, D. J.; Fiolhais, C. Atoms, molecules, solids, and surfaces: Applications of the generalized gradient approximation for exchange and correlation. Phys. Rev. B: Condens. Matter Mater. Phys. 1992, 46, 6671 .

(31) Grimme, S. Semiempirical GGA-type density functional constructed with a long-range dispersion correction. J. Comput. Chem. 2006, 27, 1787-1799.

(32) Kresse, G.; Furthmüller, J. Efficient iterative schemes for ab initio total-energy calculations using a plane-wave basis set. Phys. Rev. B: Condens. Matter Mater. Phys. 1996, 54, 11169.

(33) Kresse, G.; Furthmüller, J. Efficiency of ab-initio total energy calculations for metals and semiconductors using a plane-wave basis set. Comput. Mater. Sci. 1996, 6, 15-50. 
(34) Blöchl, P. E. Projector augmented-wave method. Phys. Rev. B: Condens. Matter Mater. Phys. 1994, 50, 17953.

(35) Allen, F. H. The Cambridge Structural Database: a quarter of a million crystal structures and rising. Acta Crystallogr., Sect. B: Struct. Sci. 2002, 58, 380-388.

(36) Uyar, T.; El-Shafei, A.; Wang, X.; Hacaloglu, J.; Tonelli, A. E. The solid channel structure inclusion complex formed between guest styrene and host $\gamma$-cyclodextrin. J. Inclusion Phenom. Mol. Recognit. Chem. 2006, 55, 109-121.

(37) Cecen, F.; Aktas, O. Activated carbon for water and wastewater treatment: Integration of adsorption and biological treatment. John Wiley \& Sons: 2011.

(38) Alsbaiee, A.; Smith, B. J.; Xiao, L.; Ling, Y.; Helbling, D.; Dichtel, W. R. Rapid removal of organic micropollutants from water by a porous b-cyclodextrin polymer. Nature 2015, 529, 190-194.

(39) Ernstberger, B.; Krause, H.; Kiermeier, A.; Neusser, H. Multiphoton ionization and dissociation of mixed van der Waals clusters in a linear reflectron time-of-flight mass spectrometer. J. Chem. Phys. 1990, 92, 5285-5296.

(40) Yeh, J.-H.; Shen, T.-L.; Nocera, D.; Leroi, G.; Suzuka, I.; Ozawa, H.; Namuta, Y. Resonance two-photon ionization spectroscopy of the aniline dimer. J. Phys. Chem. 1996, 100, 4385-4389.

(41) http://www.molinspiration.com/cgi-bin/properties.

(42) Rekharsky, M. V.; Inoue, Y. Complexation Thermodynamics of Cyclodextrins. Chem. Rev. 1998, 98, 1875-1918.

(43) Ito, S.; Kogame, C.; Akashi, M.; Kida, T. Facile synthesis of novel cyclodextrin dimer capsules and their inclusion ability towards aromatic guests in a nonpolar solvent. Tetrahedron Lett. 2016, 57, $5243-5245$. 